\title{
Chronic effects of streptozotocin diabetes on myocardial sensitivity in the rat
}

\author{
S. Ramanadham ${ }^{1}$ and T. E. Tenner, $\mathrm{Jr}^{2}$ \\ ${ }^{1}$ Faculty of Pharmaceutical Sciences, University of British Columbia, Vancouver, British Columbia, Canada and \\ ${ }^{2}$ Texas Tech University Health Sciences Center, Lubbock, Texas, USA
}

Summary. One month after streptozotocin treatment, basal rate in spontaneously beating right atria was decreased and basal developed force in electrically-driven right ventricular tissue was increased. Atrial sensitivity to the chronotropic effects of isoproterenol was not altered. In contrast, sensitivity in ventricular tissue to the inotropic effects of isoproterenol was decreased while sensitivity to calcium was increased. Associated with these changes was a decrease in myocardial $\beta$ adrenoceptor density. Data obtained 3 and 6 months after streptozotocin treatment were similar to the observed alter- ations at 1 month. These results suggest that alterations in the chronotropic and inotropic responses that are expressed within 1 month after streptozotocin treatment do not significantly progress during the 6 months following induction of diabetes. They therefore reveal the independence of myocardial alterations from age of the animal and duration of diabetes (up to 6 months).

Key words: Streptozotocin, heart, isoproterenol, calcium, $\beta$ adrenoceptor, temporal.
Clinical observations reveal an increase in the incidence of cardiomyopathy among diabetic patients [1-4]. Over the past decade, studies using the rat-diabetic model have demonstrated rapid development of cardiomyopathy after either alloxan or streptozotocin (STZ) treatment. Bradycardia, a consistent expression of experimental diabetes [5-9] has been reported to occur as early as 4 days after induction of diabetes [10]. Depressed ventricular function initially observed in dogs [11] has also been shown to be a major manifestation of diabetes in rats [12-15].

There are few studies, however, dealing with the temporal relationship between experimental diabetes and ventricular dysfunction. In one study, depressed rat left ventricular papillary muscle function observed in 5-week STZ-diabetic animals was not found to deteriorate further as the duration of diabetes was increased to 30 weeks [16]. In a separate study, an absence of a further decrease in whole heart function in response to high atrial filling pressures after initial depression at 100 days after STZ treatment was reported [17].

Previous studies in our laboratory using 1-month STZ-diabetic rats revealed the development of subsensitivity in isolated right ventricular tissue to the inotropic effects of isoproterenol [18]. The subsensitivity phenomenon was accompanied by a decrease in $\beta$-adrenoceptor number, and was also associated with supersensitivity to the inotropic effects of calcium [19]. The present study was initiated to determine the influence of a chronic diabetic state on isolated myocardial tissue responsiveness and sensitivity to chronotropic and inotropic agonists.

\section{Materials and methods}

\section{Induction of experimental diabetes mellitus}

Male Sprague-Dawley rats (150-200 g) were used in the present study. Streptozotocin (STZ, a gift from the Upjohn Co., Kalamazoo, Mich., USA) was dissolved in citrate buffer $(0.10 \mathrm{~mol} / 1$ citric acid and $0.10 \mathrm{~mol} / 1$ sodium citrate, $\mathrm{pH} 4.5$ ). One group of animals received $65 \mathrm{mg} / \mathrm{kg} \mathrm{STZ}$ through the tail vein [20]. A second group of animals, which were administered an equal volume of vehicle, served as agematched controls. Streptozotocin-treated and control animals were housed separately, two per cage, under alternating 12-h light and dark periods. The animals were maintained with free access to food (Purina Rat Chow, St. Louis, Mo, USA) and water for up to 6 months after treatment. At various times (1,3 and 6 months) after STZ treatment, the animals were killed via decapitation and exsanguination.

\section{Verification of the diabetic state}

Rate of growth, plasma glucose and glycosylated haemoglobin $\left(\mathrm{HbA}_{1}\right)$ levels were used to confirm the presence of diabetes mellitus after STZ treatment. Plasma glucose levels were determined in fresh blood samples as described previously $[19,21]$. Glycosylated haemoglobin levels were determined using a Glyc-Affin column separation system obtained from ISO Lab Inc. (Akron, Ohio, USA). 


\section{Tissue preparations}

Isolation of cardiac tissues was done according to our earlier described procedure [19]. At the time of killing, hearts were excised and immediately placed in a beaker containing cold oxygenated Chenoweth-Koelle solution ( $\mathrm{pH} 7.4)$ consisting of (mmol/1): $\mathrm{NaCl}(120.0)$; $\mathrm{KCl}(5.6) ; \mathrm{CaCl}_{2}(2.0) ; \mathrm{MgCl}_{2}(2.1) ; \mathrm{NaHCO}_{3}$ (25.0); and dextrose (9.7). After expressing blood from the heart, the right atria was carefully dissected from the ventricles. The atrial tissue was then transferred to a fresh beaker containing cold Chenoweth-Koelle solution, and excess fat and the aorta were trimmed off. One end of the atrial tissue was then attached to a tissue-electrode assembly and the other to a force-displacement transducer connected to a Grass Model 79D polygraph four-channel recorder (Quincy, Mass, USA). A triangular shaped piece of right ventricular tissue was also obtained and mounted onto a similar assembly with two platinum electrodes. The other end was attached to a Grass FT.03 force-displacement transducer that was connected to the polygraph. The tissue preparations were equilibrated at $37^{\circ} \mathrm{C}$ for $1 \mathrm{~h}$ in 20 or $50 \mathrm{ml}$ baths of Chenoweth-Koelle solution under constant oxygenation $\left(95 \% \mathrm{O}_{2}\right.$ and $\left.5 \% \mathrm{CO}_{2}\right)$. During this period, Chenoweth-Koelle solution in the tissue bath was replaced every $10 \mathrm{~min}$. Resting tensions in atria of $1 \mathrm{~g}$ and in right ventricle of $2 \mathrm{~g}$ were maintained throughout the experiment. After $30 \mathrm{~min}$ of equilibration, the ventricular strips were stimulated electrically via the punctate platinum electrodes (at a frequency of $1.6 \mathrm{~Hz}, 2$ to $8 \mathrm{~V}$, and a duration of $5 \mathrm{~ms}$ ). At the end of the equilibration period, basal rate in spontaneously beating atria and basal developed force in right ventricular tissue were recorded. Atrial preparations were used to study chronotropic responses and right ventricular tissue preparations to study inotropic responses. In addition, basal heart rates were recorded under pentobarbital $(50 \mathrm{mg} / \mathrm{kg})$ or urethane $(1.5 \mathrm{~g} / \mathrm{kg})$ anaesthesia. Pentobarbital was used initially and was subsequently replaced by urethane (during the 3- and 6-month studies) due to its longer duration of action.

\section{Agonist dose-response curves}

Chronotropic and inotropic responses to isoproterenol: The $\beta$-adrenoceptor agonist, isoproterenol (Sigma, St. Louis, Mo, USA), was prepared as a stock solution in acidifed saline $(\mathrm{NaCl}, 0.9 \%$; ascorbic acid, $0.4 \mathrm{mg} / \mathrm{dl} ; \mathrm{pH} 6.0)$. The appropriate dilutions $\left(3 \times 10^{-10}-10^{-5} \mathrm{~mol} / 1\right)$ were made in Chenoweth-Koelle solution buffer. Chronotropic responses to cumulative additions of isoproterenol in isolated atrial and right ventricular tissues, respectively, were recorded when the responses had reached a steady-state level.

\section{Inotropic response to calcium}

At the end of the equilibration period, the concentration of calcium in the bathing medium was decreased from 2.00 to $0.02 \mathrm{mmol} / \mathrm{l}$. This resulted in a gradual decline of basal developed force to levels that could not be measured. Inotropic responses were obtained by cumulative additions of calcium up to $4 \mathrm{mmol} / 1$. Responses were allowed to attain a steady state level with each dose before addition of the subsequent dose.

\section{$\beta$-Adrenoceptor binding assay in the heart}

Cardiac membrane preparation: Myocardial membrane preparations for radioligand binding assays were obtained as described previously [22]. In brief, ventricular tissue obtained from a minimum of three hearts was minced in $4 \times$ (by wet weight) volume of ice-cold sucrose $(0.25 \mathrm{~mol} / \mathrm{l})$-Tris- $\mathrm{HCl}(10 \mathrm{mmol} / \mathrm{l})$ buffer $(\mathrm{pH} 7.4)$. The mince was centrifuged at $1,200 \mathrm{~g}$ for $10 \mathrm{~min}$ at $0{ }^{\circ} \mathrm{C}$. The pellet was resuspended and centrifuged again. The resulting pellet was homogenized using a Brinkman polytron $(2 \times 20 \mathrm{~s}$ at a setting of 5$)$, and centrifuged at $12,000 \mathrm{~g}$ for $10 \mathrm{~min}$. The supernatant was passed through two layers of $4 \times 4$ gauze and centrifuged at $40,000 \mathrm{~g}$ for $60 \mathrm{~min}$. The pellet consisting of the cardiac membrane fraction was resuspended and washed in
Tris- $\mathrm{HCl}(50 \mathrm{mmol} / \mathrm{l})-\mathrm{MgCl}_{2}(10 \mathrm{mmol} / \mathrm{l})$ buffer $(\mathrm{pH} 7.4)$ and centrifuged at $40,000 \mathrm{~g}$. This step was repeated twice. Membrane protein concentration was measured by the Lowry method [23]. The pellet was resuspended to give $2 \mathrm{mg}$ protein $/ \mathrm{ml}$. A $100 \lambda$ aliquot of homogenate containing 100 to $200 \mu \mathrm{g}$ of protein was used for the $\beta$-adrenoceptor assay.

$\beta$-Adrenoceptor binding assay: $\beta$-Adrenoceptor assays were performed by incubating protein with $\left[{ }^{3} \mathrm{H}\right]-\mathrm{DHA}$ (New England Nuclear, Boston, Mass, USA; dihydroalprenolol, 0.3-15.0 nmol/1). Non-specific binding was measured in the presence of propranolol (Sigma; $10 \mu \mathrm{mol} / \mathrm{l}$ ) [24]. The binding assay was carried out at $37^{\circ} \mathrm{C}$ for $15 \mathrm{~min}$ in a total volume of $150 \lambda$. The reaction was terminated with $4 \times 3 \mathrm{ml}$ of icecold Tris- $\mathrm{McCl}_{2}$ buffer ( $\mathrm{pH} 7.4$ ), followed by rapid vacuum filtration through GF/C filters. The radioactivity $\left({ }^{3} \mathrm{H}\right)$ bound to protein was measured using a scintillation counter. Specific binding (3-7\% of total cpm) was determined by subtracting non-specific binding $(1-2 \%$ of total cpm) from total binding. Binding sites and affinity for $\left[{ }^{3} \mathrm{H}\right]-\mathrm{DHA}$ were determined according to Scatchard analysis [25].

\section{Statistical analysis}

All results were converted to the mean and standard error of the mean. Geometric mean effective concentration $\left(\mathrm{EC}_{50}\right)$ values were used to measure changes in sensitivity [26]. Student's t-test was used to determine significance between drug-treated and age-matched control groups. Results from temporal studies were analyzed using analysis of variance and Duncan's Student's multiple range test. A $p$ value less than 0.05 was considered significant.

\section{Results}

\section{Streptozotocin and indices of diabetes mellitus}

Streptozotocin-treated animals exhibited polyphagia, polydipsia, hyperphagia, lethargy, discoloration of fur and were found to develop cataracts between 3 and 6 months after STZ treatment. Decreased rate of growth and elevations in blood glucose and glycosylated haemoglobin levels were also observed in the STZ-treated animals relative to age-matched controls (Fig. 1).

\section{Chronotropic and inotropic responses in the heart}

Temporal in vivo heart rates. In vivo heart rates were found to be consistently decreased $(p<0.05)$ at all studied periods in the STZ groups relative to the agematched control groups. The heart rate values (beats/ min) recorded in the control (C) and STZ groups at 1,3 and 6 months, respectively, were as follows: C (3) $390 \pm 7$ and STZ (4) $288 \pm 19$; C (4) $375 \pm 24$ and STZ (5) $279 \pm 14 ; \mathrm{C}$ (4) $333 \pm 5$ and STZ (7) $229 \pm 25$.

Temporal chronotropic responses in spontaneously beating right atria: Chronotropic responses to isoproterenol obtained at 1,3 and 6 months are shown in Table 1 . Basal spontaneous atrial rate in the control group at 6 months was found to be greater $(p<0.05)$ than at 3 months. In the STZ group, basal atrial rate at 1 and 6 months was found to be greater $(p<0.05)$ than at 3 months. Maximum chronotropic responses to isoproterenol in the control and STZ groups at 6 months were 
found to be greater $(p<0.05)$ than at 1 and 3 months. Sensitivity to isoproterenol in the control group at 1 and 3 months was found to be greater (i.e. lower geometric mean $\mathrm{EC}_{50}, p<0.05$ ) than at 6 months. Sensitivity of the STZ group at 3 months was found to be greater $(p<$ $0.05)$ than at 6 months.

Basal spontaneous atrial rate in tissues isolated from STZ-treated animals was significantly lowered $(p<$
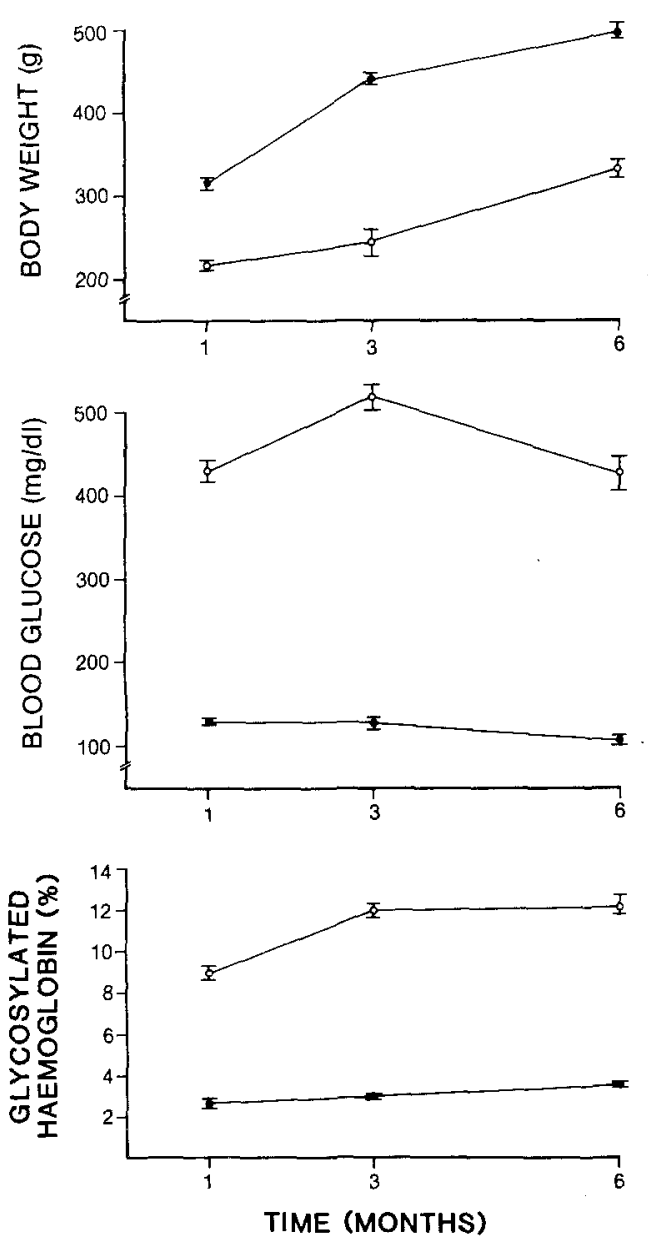

Fig. 1. Temporal body weight, blood glucose and glycosylated haemoglobin measurements. Data were obtained from 1-,3- and 6-month STZ-treated $(O-O) \quad(n=15)$ and age-matched control $(n=25)$ animals
$0.05)$ relative to the age-matched control groups at all studied periods. Maximum chronotropic response to isoproterenol in the STZ group was found to be similarly depressed $(p<0.05)$ at 1 and 6 months when compared with the age-matched control groups. However, sensitivity to isoproterenol was not altered at any time after STZ treatment.

Temporal inotropic responses in electrically-driven right ventricle: Relative to the age-matched control groups, basal developed force in tissues isolated from STZtreated animals was found to be elevated at all time periods, $p<0.05$. Data $(\mathrm{g})$ in the control $(\mathrm{C})$ and $\mathrm{STZ}$ groups are representative of tissues used to obtain responses to isoproterenol or calcium at 1,3 and 6 months, respectively: C( 30) $0.52 \pm 0.05$ and STZ (52) $0.80 \pm 0.05 ; \mathrm{C}(20) 0.41 \pm 0.05$ and STZ (31) $0.92 \pm 0.06$; C (28) $0.69 \pm 0.08$ and STZ (24) $0.91 \pm 0.07$.

Maximum responses to the inotropic effects of isoproterenol were not found to be altered by STZ treatment at 1 and 6 months, but increased at 3 months relative to the age-matched control groups. The maximal responses (g) obtained in the control (C) and STZ groups at 1,3 and 6 months, respectively, were as follows: C (19) $1.33 \pm 0.15$ and STZ (34) $1.39 \pm 0.08$; C (11) $1.05 \pm 0.15$ and STZ (19) $1.84 \pm 0.13, p<0.05$; C (8) $1.28 \pm 0.10$ and STZ (8) $1.65 \pm 0.15$.

Dose-response curves to isoproterenol obtained in the STZ groups were shifted to the right of the corresponding age-matched control groups at all time periods (Fig. 2), indicative of subsensitivity to the inotropic effects of isoproterenol. The decrease in sensitivity to isoproterenol was a reflection of higher geometric mean $\mathrm{EC}_{50}$ values obtained in the $\mathrm{STZ}$ groups relative to the age-matched control groups (Table 2).

Comparison of the basal developed force values obtained over the 6-month period with corresponding isoproterenol $\mathrm{EC}_{50}$ values revealed the persistence of subsensitivity of the STZ group relative to the control group over the range of basal developed forces observed (Fig. 3).

Maximum inotropic responses to calcium in the STZ group were not found to be altered at 1 and

Table 1. Temporal chronotropic parameters of right atria to isoproterenol

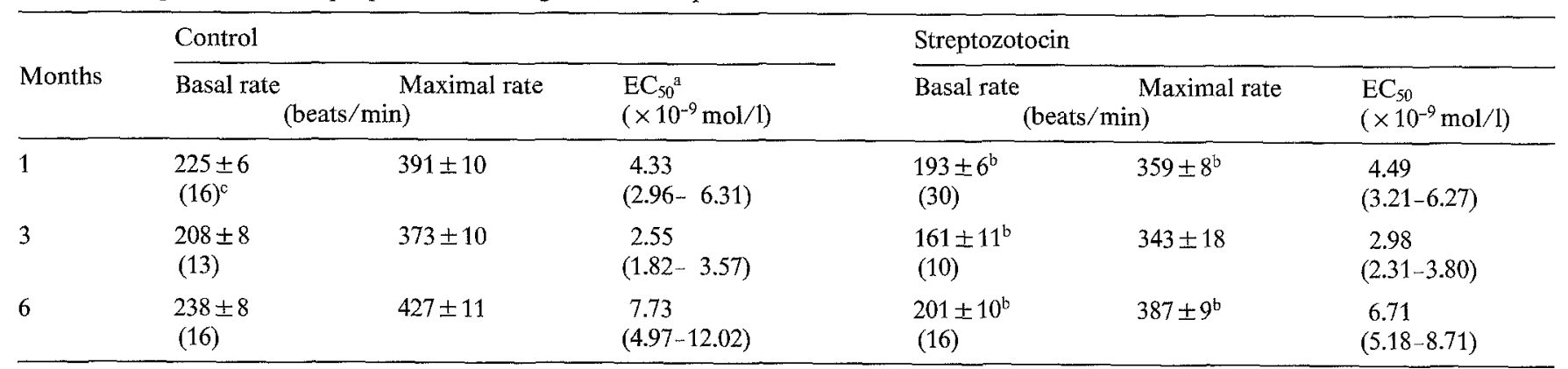

${ }^{\mathrm{a}}$ Geometric mean $\mathrm{EC}_{50}$ values plus $95 \%$ confidence intervals. ${ }^{\mathrm{b}}$ Streptozotocin group significantly different from age-matched control group, $p<$ $0.05 .{ }^{\mathrm{c}}$ Number of animals 
Table 2. Temporal in vitro inotropic sensitivity ${ }^{\mathrm{a}}$ of right ventricular tissue to isoproterenol and calcium

\begin{tabular}{|c|c|c|c|c|}
\hline \multirow[t]{2}{*}{ Months } & \multicolumn{2}{|c|}{ Isoproterenol $\left(\times 10^{-8} \mathrm{~mol} / \mathrm{l}\right)$} & \multicolumn{2}{|c|}{ Calcium $(\mathrm{mmol} / \mathrm{l})$} \\
\hline & Control & Streptozotocin & Control & Streptozotocin \\
\hline 1 & $\begin{array}{l}2.68 \\
(2.09-3.44) \\
(19)^{\mathrm{c}}\end{array}$ & $\begin{array}{l}7.39^{\mathrm{b}} \\
(5.20-10.49) \\
(34)\end{array}$ & $\begin{array}{l}2.03 \\
(1.82-2.27) \\
(11)\end{array}$ & $\begin{array}{l}1.50^{\mathrm{b}} \\
(1.36-1.64) \\
(18)\end{array}$ \\
\hline 3 & $\begin{array}{l}3.63 \\
(2.67-4.94) \\
(11)\end{array}$ & $\begin{array}{l}8.38^{\mathrm{b}} \\
(5.81-11.90) \\
(19)\end{array}$ & $\begin{array}{l}2.12 \\
(1.75-2.57) \\
(9)\end{array}$ & $\begin{array}{l}1.51^{\mathrm{b}} \\
(1.22-1.88) \\
(12)\end{array}$ \\
\hline 6 & $\begin{array}{l}4.17 \\
(2.97-7.04) \\
(8)\end{array}$ & $\begin{array}{l}11.10^{\mathrm{b}} \\
(7.20-17.10) \\
(8)\end{array}$ & $\begin{array}{l}2.06 \\
(1.88-2.25) \\
(20)\end{array}$ & $\begin{array}{l}1.69^{b} \\
(1.56-1.83) \\
(16)\end{array}$ \\
\hline
\end{tabular}

${ }^{a}$ Geometric mean $\mathrm{EC}_{50}$ values plus $95 \%$ confidence intervals. ${ }^{b}$ Streptozotocin group significantly different from age-matched control group, $p<0.05$. Number of animals
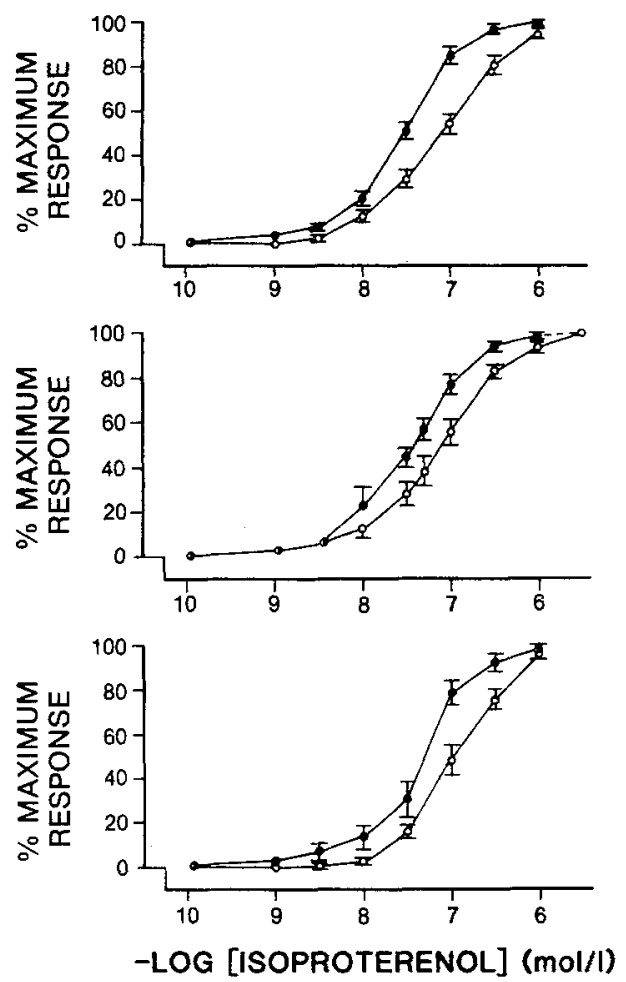

Fig. 2. Temporal percent maximum responses in right ventricular strips to isoproterenol. Dose-response curves were obtained using right ventricular strips, isolated from STZ-treated (O-O) and agematched control (-) animals, to determine the inotropic effects of isoproterenol $\left(10^{-10}-3 \times 10^{-6} \mathrm{~mol} / 1\right)$ at 1,3 and 6 months. $N$ values for control and STZ groups, respectively, at the three time periods were 19 and $34 ; 11$ and $19 ;$ and 8 and 8

6 months but increased at 3 months relative to the agematched control groups. The maximum responses $(\mathrm{g})$ obtained in the control (C) and STZ groups at 1,3 and 6 months, respectively, were as follows: $C$ (11) $1.07 \pm$ 0.14 and STZ (18) $1.14 \pm 11 ; C$ (9) $1.01 \pm 0.12$ and STZ (12) $1.62 \pm 0.11, p<0.05$; C (20) $1.42 \pm 0.15$ and STZ (16) $1.41 \pm 0.09$.

In contrast to isoproterenol, dose-response curves to $\mathrm{Ca}^{2+}$ obtained in the STZ groups were found to be shifted to the left of the corresponding age-matched control groups at all time periods (Fig.4), indicative of

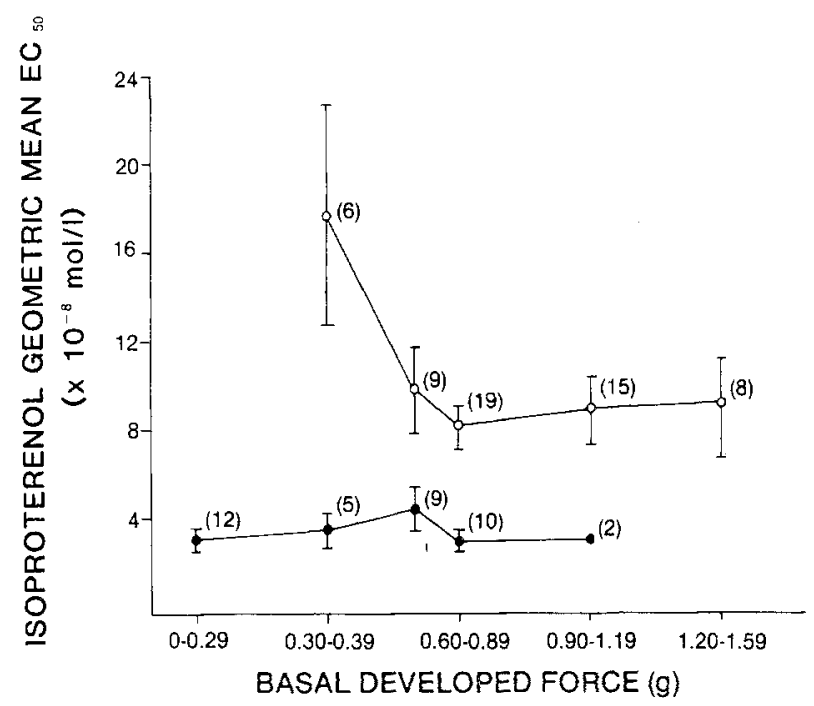

Fig. 3. Relationship between isoproterenol geometric mean $\mathrm{EC}_{50}$ values and corresponding basal developed forces. The values represent a composite of data obtained using right ventricular strips isolated from 1-, 3- and 6-month STZ-treated (O-O) and age-matched control (-) animals. Values in parentheses represent number of tissues

supersensitivity to the inotropic effects of $\mathrm{Ca}^{2+}$. The increased sensitivity to $\mathrm{Ca}^{2+}$ was a reflection of lower geometric mean $\mathrm{EC}_{50}$ values obtained in the STZ groups relative to the age-matched control groups (Table 2).

Comparison of the basal developed force values obtained over the 6-month period with corresponding $\mathrm{Ca}^{2+} \mathrm{EC}_{50}$ values revealed the persistence of supersensitivity of the STZ group relative to the control group over the range of basal developed forces observed (Fig. 5). 

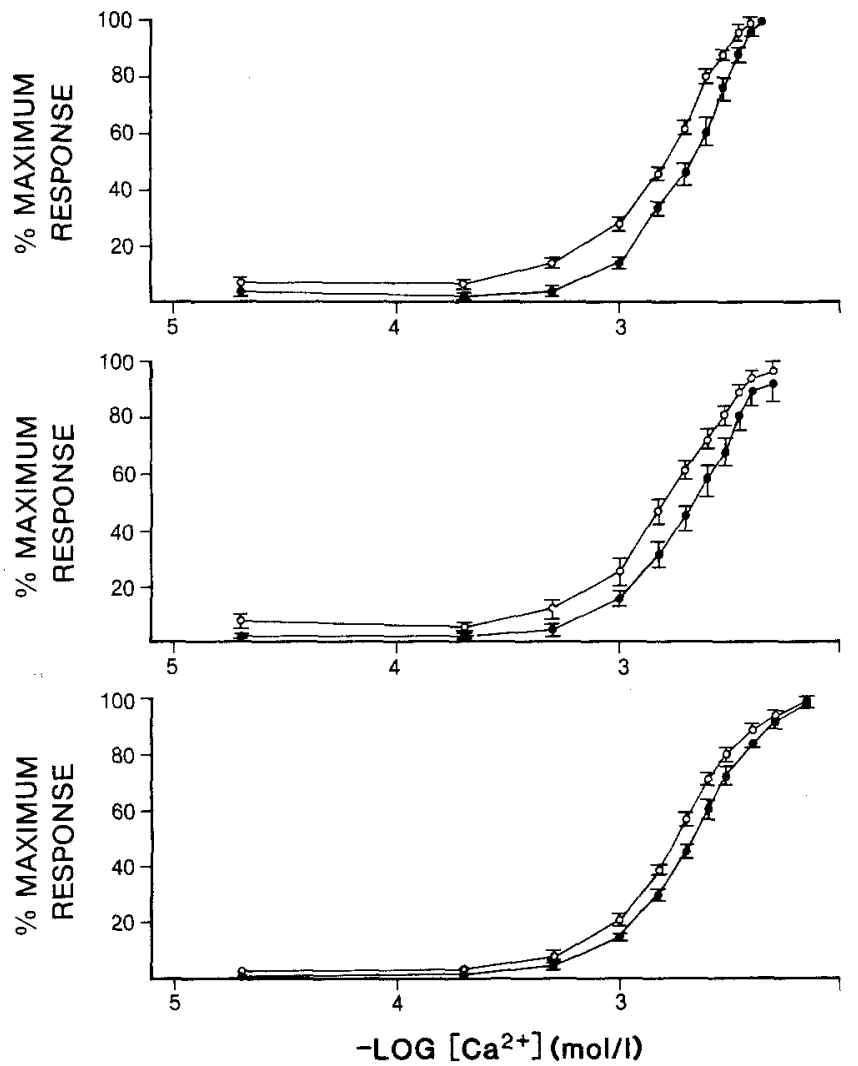

Fig.4. Temporal percent maximum response in right ventricular strips to calcium $\left(\mathrm{Ca}^{2+}\right)$. Dose-response curves were obtained using right ventricular strips, isolated from 1-, 3- and 6-month STZ-treated $(\mathrm{O}-\mathrm{O})$ and age-matched control (-) animals, to determine the inotropic effects of $\mathrm{Ca}^{2+}(0.02-5.00 \mathrm{mmol} / \mathrm{l})$ at 1,3 and 6 months. Inotropic responses $(\mathrm{g})$ obtained with $2.00 \mathrm{mmol} / 1 \mathrm{Ca}^{2+}$ were not found to be significantly different from basal developed force (BDF). (1 month - C (11): BDF, $0.63 \pm 0.08 ; 2.00 \mathrm{mmol} / 1,0.52 \pm 0.08$. STZ (18): BDF, $0.87 \pm 0.07 ; 2.00 \mathrm{mmol} / 1,0.70 \pm 0.06 .3$ months $-\mathrm{C}(9)$ : BDF, $0.40 \pm 0.06 ; 2.00 \mathrm{mmol} / 1,0.46 \pm 0.08$ and STZ (12): BDF, $0.93 \pm 0.10 ; 2.00 \mathrm{mmol} / 10.99 \pm 0.09 .6$ months $-\mathrm{C}(20): \mathrm{BDF}, 0.77 \pm$ $0.11 ; 2.00 \mathrm{mmol} / 1,0.69 \pm 0.11$ and STZ (16): BDF, $1.01 \pm 0.11$; $2.00 \mathrm{mmol} / 1,0.82 \pm 0.08)$

\section{Myocardial $\beta$-adrenoceptor estimations}

$\beta$-Adrenoceptor density, as determined by the estimation of $\left[{ }^{3} \mathrm{H}\right]$-DHA binding sites, was found to be decreased $(p<0.05)$ in the $\mathrm{STZ}$ groups at all time periods relative to the age-matched control groups (Table 3 ). However, neither affinity (KD) of the receptor, nor heart protein yield, were significantly altered by STZ treatment.

\section{Temporal relationships in the ventricle}

The following parameters were not found to be significantly altered with time in either control or STZ groups: basal developed force, and inotropic sensitivity to isoproterenol and calcium. While maximum responses to isoproterenol and calcium in the control groups were not affected by the duration of study they were found to

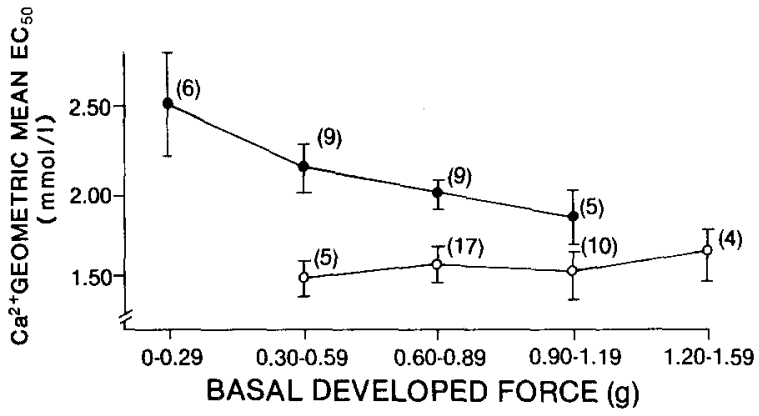

Fig.5. Relationship between $\mathrm{Ca}^{2+}$ geometric mean $\mathrm{EC}_{50}$ values and corresponding basal developed forces. The values represent a composite of data obtained using right ventricular strips isolated from 1-, 3- and 6-month STZ-treated (O-O) and age-matched control (-0) animals. Values in parentheses represent number of tissues

Table 3. Temporal comparisons of $\left[{ }^{3} \mathrm{H}\right]-\mathrm{DHA}$ binding sites, affinities and protein yields

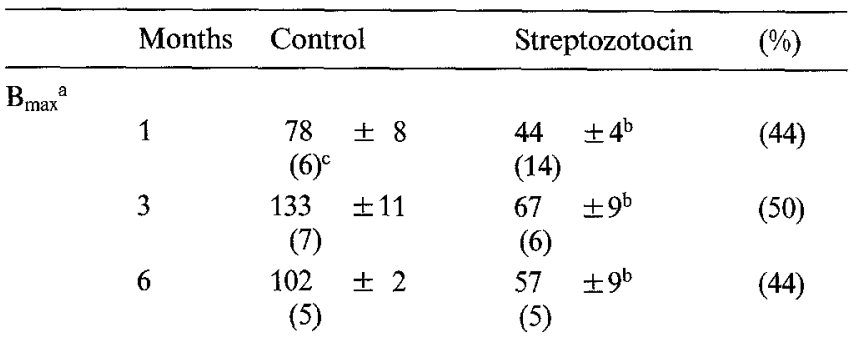

$\mathrm{KD}^{\mathrm{d}}$

$\begin{array}{lll}1 & 3.99 \pm 0.70 & 3.10 \pm 0.57 \\ 3 & 5.36 \pm 0.60 & 3.92 \pm 0.97 \\ 6 & 2.80 \pm 0.59 & 2.50 \pm 0.44\end{array}$

Yield $^{\mathrm{C}}$

$\begin{array}{lll}1 & 1.14 \pm 0.10 & 1.51 \pm 0.21 \\ 3 & 0.93 \pm 0.11 & 0.97 \pm 0.12 \\ 6 & 1.45 \pm 0.12 & 1.49 \pm 0.11\end{array}$

${ }^{\mathrm{a}}\left[{ }^{3} \mathrm{H}\right]-\mathrm{DHA}$ binding sites determined as $\mathrm{fmol} / \mathrm{mg}$ protein. ${ }^{\mathrm{b}}$ Streptozotocin group significantly different from age-matched control group, $p<0.05$. ${ }^{\mathrm{C}}$ Represents number of assay groups. Each group contained a minimum of three hearts. ${ }^{\mathrm{d}}$ Affinity for $\left[{ }^{3} \mathrm{H}\right]$-DHA (nmol/l). ${ }^{\mathrm{e}} \mathrm{De}$ termined as total $\mathrm{mg}$ protein/wet wt. of hearts/number of hearts

be elevated in the STZ group at 3 months when compared with 1 month.

The variability in Bmax values observed among the control and STZ groups was related to the fact that the 1-, 3- and 6-month studies were performed separately and at different times. However, the percentage decrease in $\beta$-adrenoceptor density in the STZ groups relative to the age-matched control groups remained similar.

\section{Discussion}

The "classical signs" of human diabetes include elevations in blood glucose, glycosuria, polydipsia, polyuria and hyperphagia [27]. In the present study, these features were observed in the rat after streptozotocin administration. Blood glucose levels in the STZ group 
were found to be significantly elevated when first determined at 3 days. During the course of the 6 months, they remained elevated in the absence of spontaneous recovery from the diabetogenic effects of STZ, similar to previous studies [16, 17, 28]. Glycosylated haemoglobin, in contrast to blood glucose, did not reach a steady-state level until 3 months after STZ treatment. This is expected, since glycosylation of haemoglobin proceeds continuously and irreversibly during the 3-month life span of a mammalian erythrocyte [29].

Earlier studies in our laboratory demonstrated myocardial abnormalities in rats 1 month after induction of diabetes with STZ. These included: bradycardia, elevated ventricular basal developed force, inotropic subsensitivity to isoproterenol, inotropic supersensitivity to calcium and decreased $\beta$-adrenoceptor density $[18,19]$. The diabetic state produced in the present study, as described earlier, was associated with a decreased rate of growth. The deleterious effects of chronic under-nutrition on heart function, while not examined in the present study, have been investigated in other laboratories. Streptozotocin-induced depressions in myocardial function $[14,16]$ and biochemical parameters such as actinomysin calcium-ATPase activity [30] and $\beta$-adrenoceptor density [31] were not found to be present in non-diabetic rats whose food had been restricted. Thus, it might be proposed that diabetes-induced malnutrition is not the major cause of myocardial abnormalities observed in the present study. These alterations were also found not to be a result of direct cardiotoxic effects of STZ $[32,33]$. The objective of the present study, therefore, was to distinguish between the effects of the diabetic state and duration of diabetes in the heart.

Relative to the age-matched control groups, bradycardia, decreased maximum chronotropic responses to isoproterenol (with the exception of 3 months) and absence of sensitivity changes to the chronotropic effects of isoproterenol were observed at all time periods in the STZ group. Even though some variation within the control and STZ groups was apparent during the course of the study, the differences between the two remained.

Bradycardia has been observed as early as 4 days after STZ treatment [10]. In the uncontrolled state, lowered heart rates persisted for the duration of the study (14 weeks). This is in agreement with the data obtained in the present study, which revealed a consistent occurrence of bradycardia for 24 weeks after STZ treatment. Possibility of damage to atrial tissue during isolation resulting in bradycardia was dismissed when in vivo heart rates were also found to be depressed in the STZ groups. In addition, the data obtained under in vivo conditions indicated that bradycardia was not an indirect result of differences in the ion or glucose concentrations used in the buffer medium under in vitro conditions.

Bradycardia has been proposed to be due to alterations in SA nodal electrical activity as a result of hyperglycaemia [34, 35], reduced myocardial lipid metabo- lism $[11,36]$, or hypothyroidism $[37,38]$. The mechanism(s) by which bradycardia is produced by these abnormalities, however, has not yet been elucidated.

The present observations of a lack of change in chronotropic sensitivity is in contrast to the findings of Foy and Lucas [6]. These authors reported an elevated basal contractile force associated with isolated auricle subsensitivity to isoproterenol. One difference in the two studies is the concentration of glucose used in the medium. Foy and Lucas [6] used a concentration of $5.6 \mathrm{mmol} / \mathrm{l}$, while in the present study $9.7 \mathrm{mmol} / 1$ was used. It has been suggested that an increase in work by hearts of diabetic rats raised glucose uptake to normal [39]. Thus, it is reasonable to speculate that the glucose concentration used in studies performed by Foy and Lucas [6], as opposed to the present study, was a limiting factor. Whether this is an important factor in regulating sensitivity to isoproterenol is not known.

Ventricular alterations observed in the 1-month STZ-treated animals were also evident at 3 and 6 months. Elevations in basal developed force, and inotropic subsensitivity to isoproterenol and supersensitivity to calcium were not found to be significantly influenced by the duration of diabetes. Decreased $\beta$-adrenoceptor density in the absence of a change in receptor affinity was also persistent during the 6-month period.

This lack of significant progression in myocardial abnormalities is consistent with previous long-term studies. Fein et al. [16], using the rat left ventricular papillary muscle preparation, reported depressed myocardial mechanics as early as 5 weeks after STZ treatment. The changes, however, did not worsen as the duration of diabetes was increased to 35 weeks. Similarly, Vadlamudi et al. [17] observed depressed positive and negative rate of force development in the working heart preparation of rats at 13 weeks after induction of diabetes with STZ. However, as the study was extended to 52 weeks, further depression of function was not evident.

The present data suggest that alterations in myocardial inotropic sensitivity in the STZ group are not related to elevations in the basal developed force. Other data obtained in our laboratory indicate that the functional alterations in the ventricle are not due to changes in the tissue norepinephrine content and release from the heart [18], choices in the resting tension and frequency of stimulation [19], the glucose concentration in the medium [33] or to direct cardiotoxic effects of STZ $[32,33]$.

In view of the presence of ventricular subsensitivity to isoproterenol in the diabetic hearts, it is of interest to note that decreases in isoproterenol-stimulated adenylate cyclase activation [40], cyclic AMP responses [40-42] and calcium influx [43] have also been observed in STZ-diabetic animals. The possibility of these alterations influencing inotropic sensitivity in diabetic animals to $\beta$-stimulation is currently under investigation. Involvement of diabetes-induced alterations in the $\beta$ adrenoceptor system contributing to the subsensitivity 
phenomenon is also suggested by the concomitant occurrence of supersensitivity to the receptor-independent inotropic effects of calcium. The question of whether the changes in myocardial sensitivity to calcium and isoproterenol are occurring independently or in a compensatory fashion will be addressed in future studies.

In summary, the present study reveals that myocardial alterations observed after STZ treatment are independent of duration of diabetes (up to 6 months). Increase in the age of the animal also does not appear to contribute to the observed alterations since the same parameters studied in ventricular tissue obtained from control animals did not progress significantly with time. They further indicate that the 1-month diabetic state is a suitable model for studies dealing with the elucidation of the factor(s) responsible for myocardial abnormalities observed after STZ treatment.

Acknowledgements. The authors wish to thank Ms. E. Thomas and Ms. C. Anderson for invaluable assistance in the preparation of this manuscript and Ms. J. Young and Ms. B. J. Riker for technical assistance. The work was supported in part by grants from the American Heart Association, Texas Affiliate, Inc., The American Diabetes Association and NHLBI: HL 30472.

\section{References}

1. Kannel WB, Hjortland M, Castelli WP (1974) The role of diabetes in congestive heart failure: the Framingham study. Am J Cardiol 34: $29-35$

2. Ahmed SS, Jakeri GA, Narang RM, Regan TJ (1975) Preclinical abnormality of left ventricular function in diabetes mellitus. Am Heart J 89: 153-358

3. Regan TJ, Lyons MM, Ahmed SS, Levinson GE, Oldewurtel HA, Ahmed MR, Haider B (1977) Evidence for cardiomyopathy in familial diabetes mellitus. J Clin Invest 60: 885-899

4. Shapiro LM, Howat AP, Calter MM (1981) Left ventricular function in diabetes mellitus I: methodology and prevalence and spectrum of abnormalities. Br Heart J 45: 122-128

5. Foy JM, Lucas PD (1976) Effect of experimental diabetes, food deprivation, and general obesity on the sensitivity of pithed rats to autonomic agents. Br J Pharmacol 57: 229-234

6. Foy JM, Lucas PD (1978) Comparison between spontaneously beating atria from control and streptozotocin diabetic rats. J Pharm Pharmacol 30: 558-562

7. Garber DW, Neely JR (1983) Decreased myocardial function and myosin ATPase in hearts from diabetic rats. Am J Physiol 244: H586-H591

8. Jackson CV, Carrier GO (1983) Influence of short-term experimental diabetes on blood pressure and heart rate in response to norepinephrine and angiotensin II in the conscious rat. J Cardiovasc Pharmacol 5: 260-265

9. Charocopos F, Gavras H (1984) Cardiovascular responses in the diabetic rat. Q J Exp Physiol 69: 463-468

10. Pfaffman MA (1980) The effects of streptozotocin-induced diabetes and insulin-treatment on the cardiovascular system of the rat. Res Commun Pathol Pharmacol 28 (1): 27-41

11. Regan TJ, Ettinger PO, Khan MI, Jesrani U, Lyons MM, Oldewurtel HA, Wever M (1974) Altered myocardial function and metabolism in chronic diabetes mellitus without ischemia in dogs. Circ Res 35: 222-237
12. Feuvray D, Idell-Wenger JA, Neely JR (1979) Effects of ischemia on rat myocardial function and metabolism in diabetes. Circ Res 44: 322-329

13. Miller TB Jr (1978) Cardiac performance of hearts from acutely insulin deficient rats. Am J Physiol 236: H808-H812

14. Penpargkul S, Schaible T, Yipintsoi T, Scheuer J (1980) The effects of diabetes on performance and metabolism of rat hearts. Circ Res 47:911-921

15. Vadlamudi R, McNeill JH (1980) Cardiac function in normal and diabetic rats. Proc West Pharmacol Soc 23: 29-31

16. Fein FS, Kornstein LB, Strobeck JE, Capasso JM, Sonnenblick EH (1980) Altered myocardial mechanics in diabetic rats. Circ Res 47: 922-933

17. Vadlamudi RVSV, Rodgers RL, McNeill JH (1982) The effect of chronic alloxan- and streptozotocin-induced diabetes on isolated rat heart performance. Can J Physiol Pharmacol 50: 902-911

18. Ramandham S, Tenner TEJr (1984) Basal developed force and inotropic characteristics of myocardial tissue isolated from streptozotocin-diabetic animals. Proc West Pharmacol Soc 27: 197-200

19. Ramanadham S, Tenner TE Jr (1983) Alterations in cardiac performance in experimentally-induced diabetes. Pharmacology 27: $130-139$

20. Junod A, Lambert AE, Orci L, Pictet R, Gonet AE, Renold AE (1967) Studies of the diabetogenic action of streptozotocin. Proc Soc Exp Biol Med 126: 201-205

21. Raabo E, Terkildsen TC (1960) On the enzymatic determination of blood glucose. Scand J Clin Lab Invest 12: 402-407

22. Tenner TE Jr, Mukherjee A, Hester RK (1982) Reserpine-induced supersensitivity and the proliferation of cardiac $\beta$-adrenoceptors. Eur J Pharmacol 77: 61-64

23. Lowry OH, Rosenbrough NJ, Farr AL, Randall RJ (1951) Protein measurement with folin phenol reagent. J Biol Chem 193: 265-275

24. Mukherjee A, Wong TM, Buje LM, Lefkowitz RJ, Wilkerson JT (1979) $\beta$-Adrenergic and muscarinic cholinergic receptor in canine myocardium. Effects of ischemia. J Clin Invest 64: $1423-1428$

25. Scatchard G (1949) The attraction of proteins for small molecules and ions. Ann NY Acad Sci 51: 660-662

26. Fleming WW, Westfall DD, De La Lande IS, Jehlett LB (1972) Log-normal distribution of equieffective doses of norepinephrine and acetylcholine. J Pharmacol Exp Ther 181: 339-345

27. Rerup CC (1970) Drugs producing diabetes through damage of the insulin secreting cells. Pharmacol Revs 22 (4): 485-518

28. Felten SY, Petersen RG, Shea PA, Besch HR Jr, Felten DL (1982) Effects of streptozotocin diabetes on the noradrenergic innervation of the rat heart. A longitudinal histofluorescence and neurochemical study. Br Res Bull (6): 593-607

29. Mangrum RE (1975) In: Mangrum RE (ed) Manual of hematology. Reston Publishing, Virginia

30. Malhotra A, Penpargkul S, Fein FS, Sonnenblick EH, Scheuer J (1981) The effect of streptozotocin-induced diabetes in rats on cardiac contractile proteins. Circ Res 49:1243-1250

31. Williams RS, Schiable TF, Scheuer J, Kennedy R (1983) Effects of experimental diabetes on adrenergic and cholinergic receptors of rat myocardium. Diabetes 32: 881-886

32. Ramandadham S, Decker P, Tenner TE Jr (1983) Effect of insulin replacement on streptozotocin-induced effects in the rat heart. Life Sci 33: 289-296

33. Ramanadham S, Young J, Tenner TE Jr (1986) Prevention of streptozotocin-induced alterations in the rat heart by 3-O-methyl glucose and insulin treatments. J Cardiovasc Pharmacol (in press)

34. McDonald TF, MacLeod DP (1973) Metabolism and the electrical activity of anoxic ventricular muscle. J Physiol 229:559-582

35. Senges J, Brachmann J, Pelzer D, Hasslacher C, Weihe E, Kubler W (1980) Altered cardiac automaticity and conduction in experimental diabetes mellitus. J Mol Cell Cardiol 12:1341-1351

36. Hearse DJ, Steward DA, Chain ED (1975) Diabetes and the survival and recovery of the anoxic myocardium. J Mol Cell Cardiol $7: 397$ 
37. Garber DW, Everett AW, Neely JR (1983) Cardiac function and myosin ATPase in diabetic rats treated with insulin, $T_{3}$ and $T_{4}$. Am J Physiol 244: H592-H598

38. Rodrigues B, Agrawal DK, McNeill JH (1985) Are elevated lipids and diabetic cardiomyopathy related. Fed Proc 44 (5): 1657 (Abstract)

39. Chain EB, Mansford KRL, Opie LH (1969) Effects of insulin on the pattern of glucose metabolism in the perfused working and Langendorff heart of normal and insulin-deficient rats. Biochem $\mathbf{J}$ 115:537-546

40. Atkins FL, Dowell RT, Love S (1985) $\beta$-Adrenergic receptors, adenylate cyclase activity and cardiac dysfunction in the diabetic rat. J Cardiovasc Pharmacol 7: 66-70

41. Ingebretsen WR Jr, Peralta C, Monsher H, Wagner LK, Ingebretsen CG (1981) Diabetes alters the myocardial cAMP-protein kinase cascade system. Am J Physiol 240: H374-H382

42. Götzsche O (1983) The adrenergic $\beta$-receptor adenylate cyclase system in heart and lymphocytes from streptozotocin diabetic rats: in vivo and in vitro evidence for a desensitized myocardial $\beta$ receptor. Diabetes 32: 1110-1116

43. Götzsche O (1983) Decreased myocardial calcium uptake after isoproterenol in streptozotocin-induced diabetic rats: studies in the in vitro perfused heart. Lab Invest 48 (2): 156-161

\section{Received: 25 April 1986}

and in revised form: 13 August 1986

Dr. S. Ramanadham

Faculty of Pharmaceutical Sciences

The University of British Columbia

2146 East Mall

Vancouver, BC

Canada V6T 1W5 